\title{
Curative Gastrectomy with Perioperative Chemotherapy Improves the Survival for Unresectable Gastric Cancer
}

\author{
YASUNORI OTOWA, SATOSHI SUZUKI, SHINGO KANAJI, HITOSHI HARADA, \\ TOMOKO TANAKA, MASASHI YAMAMOTO, YOSHIKO MATSUDA, \\ TARO OSHIKIRI, TETSU NAKAMURA and YOSHIHIRO KAKEJI \\ Division of Gastrointestinal Surgery, Department of Surgery, \\ Kobe University Graduate School of Medicine, Kobe, Japan
}

\begin{abstract}
Background/Aim: Although there are a few reports recommending gastrectomy for unresectable gastric cancer (UGC) to improve survival, the advantage of gastrectomy remains unclear. The objective of this study was to assess the meanings of the surgical intervention. Patients and Methods: Therapeutic outcomes were retrospectively evaluated in 127 patients with UGC. All patients had chemotherapy and 47 patients underwent gastrectomy. Patients were classified to three groups according to the treatment. Results: Multivariate analysis showed that gastrectomy was in independent favorable prognosis factor $(p<0.001)$ as well as performance status $0 / 1$, differentiated type, absence of distant organ metastasis, and second line chemotherapy for UGC. Among the patients with gastrectomy, $R O$ resection was an independent prognostic factor $(p=0.011)$. RO resection was mainly achieved when there was a single non-curable factor and no distant organ metastasis ( $p=0.007$ and $p=0.024$, respectively). Conclusion: Gastrectomy has an advantage in improving the survival in selected cases among UGC. If chemotherapy enables to control the non-curable factors, gastrectomy should be considered.
\end{abstract}

Although new chemotherapy regimens and molecular targeting agents have been developed, the survival for initially unresectable gastric cancer (UGC) remains dismal (1-4). The standard treatment for UGC is chemotherapy; however, recent studies showed that curative gastrectomy

Correspondence to: Yasunori Otowa, MD, Ph.D., Division of Gastrointestinal Surgery, Department of Surgery, Kobe University Graduate School of Medicine, Kusunoki-chou 7-5-2, Chuo-ku, Kobe, Hyogo 650-0017, Japan. Tel: +81 783825925, Fax: +81 783825939, e-mail: otoway@med.kobe-u.ac.jp

Key Words: Unresectable gastric cancer, preoperative chemotherapy, curative resection, gastrectomy. with curative intent following chemotherapy might have a benefit in improving the survival for UGC (5-8). Despite these reports, indication of curative gastrectomy for UGC is still unclear. Yoshida et al. proposed new biological categories for the classification of stage IV Gastric cancer (GC) (9). According to this classification, patients with potentially or marginally resectable metastasis were proposed to have chemotherapy following gastrectomy. Therefore, UGC with initially unresectable metastasis might also have an advantage improving the survival after chemotherapy followed by gastrectomy.

On the other hand, REGATTA trial denied the benefit of reduction gastrectomy for stage IV GC compared to chemotherapy alone (10). However, patients who had gastrectomy did not have preoperative chemotherapy or R0 resection that might have affected the survival. Moreover, gastrectomy is sometimes performed to control the urgent symptoms in clinical practice (11). It is not clear whether palliative gastrectomy improves the survival in such cases. In this study, we aimed to assess the benefit and indication of gastrectomy for initially UGC.

\section{Patients and Methods}

Study population. One hundred twenty-seven patients who were diagnosed initially as UGC at Kobe University Hospital during November 2002 to May 2014, were investigated in this study. The clinical stage was determined according to the Japanese classification of gastric carcinoma (12) and assessed based on esophagogastroduodenoscopy and enhanced computed tomography before treatment and intraoperative findings. All tumors were confirmed as adenocarcinoma by biopsy specimen. The presence of distant organ metastasis, positive peritoneal cytology and/or peritoneal metastasis ( $\mathrm{CY}$ and/or $\mathrm{P}$ factor), and lymph node metastasis in the extensive region (distant lymph node metastasis) were considered as non-curable clinical factors. Also, marginally resectable factors such as pancreatic head invasion and Bulky lymph node metastasis: one lymph node metastasis larger than $3 \mathrm{~cm}$ or two lymph node metastases larger than $1.5 \mathrm{~cm}$ along the celiac, splenic, common or proper hepatic arteries, were considered as non-curable 
clinical factors. All patients had chemotherapy and 47 patients underwent gastrectomy. Among the patients who underwent gastrectomy, 21 patients had preoperative and postoperative chemotherapy (Perioperative chemotherapy group), and 26 patients without it (Postoperative chemotherapy group). All other 80 patients had chemotherapy alone (Chemotherapy alone group) (Figure 1). Patients' characteristics, chemotherapeutic agents, and surgical outcomes were obtained retrospectively by studying the patient clinical charts. All study participants provided informed consent, and the study design was approved by the ethics review board at Kobe University Hospital and conforms to the provisions of the 1995 Declaration of Helsinki (UMIN000019544).

Treatment strategy. The initial treatment varied according to the period background. Until 2010, surgery was mostly chosen as an initial treatment. However, from 2011, chemotherapy was chosen as an initial treatment due to the improvement in chemotherapy. Gastrectomy was added whenever the non-curable factors disappeared or diminished in size and found resectable by extending the resection area.

Statistical analysis. The difference between groups was analyzed by using the Fisher exact test or Chi-square test and Student's T test or Mann-Whitney $U$-test. The survival time was calculated from the first visited date to our hospital to the occurrence of the event or the last known date of follow-up. The chemotherapy period was calculated from the first to the last known administration date excluding the period of surgery. Survival analysis was performed using the Kaplan-Meier method with the log-rank test. Bonferroni correction was used for multiple comparisons to test difference between the groups. Variables with a $p$-value $<0.2$ in a univariate analysis were further evaluated in a multivariate analysis using the Cox proportional hazard model to assess the predictors for survival. In all analyses, a $p<0.05$ was accepted as statistically significant. Descriptive statistics were obtained using the JMP statistical software package (JMP ${ }^{\circledR} 10$, SAS Institute Inc., Cary, NC, USA).

\section{Results}

The characteristics of patients are listed in Table I. Not all patients had peritoneal cytology test, since other non-curable factors were proven. The majority of the patients were male, performance status was $0 / 1$, and the tumor depth was $\mathrm{T} 4$ in either groups. There was a difference in patients' characteristics in $\mathrm{CY}$ and/or $\mathrm{P}$ factor and single non-curable factor between groups ( $p=0.030$ and $p=0.025$, respectively). Moreover, Bonferroni correction showed that single noncurable factor was significantly less observed in the Perioperative group than in the Chemotherapy alone group $(p=0.011)$, while there was no difference in $\mathrm{CY}$ and/or $\mathrm{P}$ factor between either groups. Majority of the patients had S-1 based chemotherapy in either groups. The median chemotherapy period of Chemotherapy alone-group was significantly shorter than the other two groups (Chemotherapy alone-group 7.2 months, Perioperative chemotherapy group 14.2 months, Postoperative chemotherapy group 14.1 months, $p<0.001)$.

One hundred nineteen patients (93.7\%) deceased and 2 patients were lost during the follow-up. Figure 2 shows the

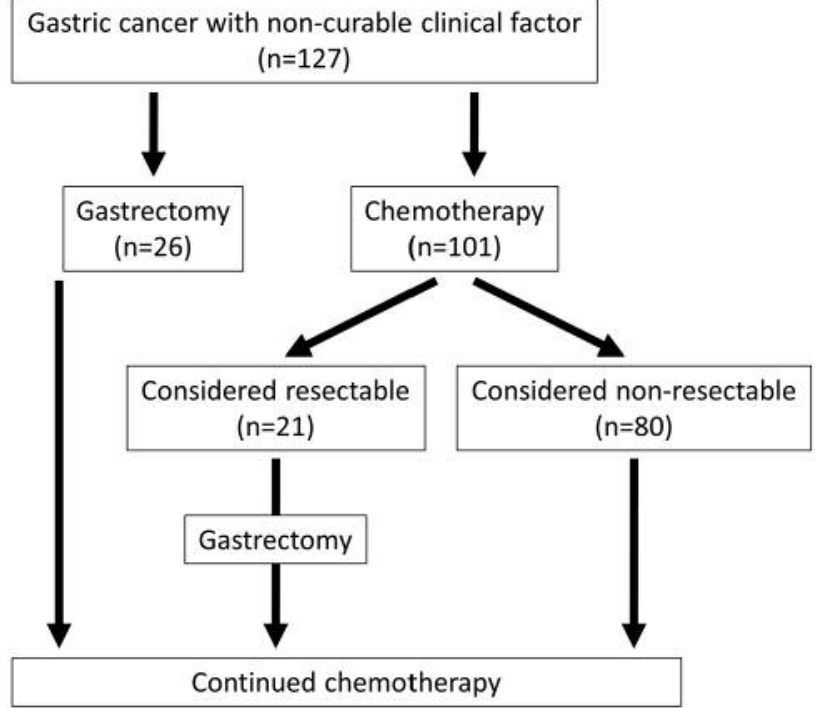

Figure 1. Diagram of the study.

overall survival (OS) between the three groups. Perioperative chemotherapy group had a longer OS than Postoperative chemotherapy group and Chemotherapy group $(p=0.009$ and $p<0.001$, respectively). Postoperative chemotherapy group had a longer OS than Chemotherapy group $(p<0.001)$. The median survival time (MST) of all patients was 1.1 years, and MST of Perioperative chemotherapy group, Postoperative chemotherapy group and Chemotherapy group was 2.8 years, 1.4 years and 0.9 year, respectively.

Univariate and multivariate analysis were performed to determine the factors that affected the survival (Table II). From the univariate analysis, gastrectomy, Performance status (PS), CY and/or P factor, distant organ metastasis, numbers of non-curable factors and second line chemotherapy were indicated as prognostic factors. Multivariate analysis showed that gastrectomy (Hazard Ratio $(\mathrm{HR})=0.242,95 \%$ confidence interval $(\mathrm{CI})=0.149-0.384$, $p<0.001)$ was an independent favorable prognostic factor as well as PS 0/1 (HR=0.252, 95\% CI $=0.123-0.551, p=0.001)$, differentiated type $(\mathrm{HR}=0.564,95 \% \mathrm{CI}=0.377-0.837$, $p=0.004)$, absence of distant organ metastasis $(\mathrm{HR}=2.573$, $95 \% \mathrm{CI}=1.579-4.257, \quad p<0.001), \quad$ and second line chemotherapy $(\mathrm{HR}=0.274,95 \% \mathrm{CI}=0.168-0.447, p<0.001)$.

Univariate and multivariate analyses were performed to determine the prognosis factors of those who underwent gastrectomy (Table III). From the univariate analysis, PS 0/1, absence of $\mathrm{CY}$ and/or P factor, single non-curable factor, R0 resection, and preoperative chemotherapy were indicated as prognostic factors. The multivariate analyses showed that $\mathrm{R} 0$ resection was associated with favorable survival $(\mathrm{HR}=0.140$, 
Table I. Patient characteristics.

\begin{tabular}{|c|c|c|c|c|}
\hline Variables & $\begin{array}{c}\text { Perioperative } \\
\text { chemotherapy group } \\
(\mathrm{n}=21)\end{array}$ & $\begin{array}{c}\text { Postoperative } \\
\text { chemotherapy group } \\
(n=26)\end{array}$ & $\begin{array}{l}\text { Chemotherapy } \\
\text { alone group } \\
(\mathrm{n}=80)\end{array}$ & $p$-Value \\
\hline Age, mean $\pm \mathrm{SD}$, years & $63.2 \pm 12.0$ & $62.6 \pm 7.6$ & $61.5 \pm 11.1$ & 0.752 \\
\hline Gender (Male) & $13(61.9 \%)$ & $23(88.5 \%)$ & $51(63.8 \%)$ & 0.031 \\
\hline Performance status $0 / 1$ & $20(95.2 \%)$ & $25(96.2 \%)$ & $71(88.8 \%)$ & 0.360 \\
\hline Histology (differentiated type) & $10(47.6 \%)$ & $10(38.5 \%)$ & $35(43.8 \%)$ & 0.812 \\
\hline $\mathrm{T} 4$ & $13(61.9 \%)$ & $7(73.1 \%)$ & $58(72.5 \%)$ & 0.624 \\
\hline \multicolumn{5}{|l|}{ Non-curable factor ${ }^{\mathrm{a}}$} \\
\hline Bulky lymph node metastasis & $3(14.3 \%)$ & $4(15.4 \%)$ & $18(22.5 \%)$ & 0.569 \\
\hline Distant lymph node metastasis & $8(38.1 \%)$ & $10(26.9 \%)$ & $40(50.0 \%)$ & 0.439 \\
\hline $\mathrm{CY}$ and/ or P factor & $5(23.8 \%)$ & $16(61.5 \%)$ & $38(47.5 \%)$ & 0.030 \\
\hline Distant organ metastasis & $9(42.9 \%)$ & $11(42.3 \%)$ & $45(56.3 \%)$ & 0.293 \\
\hline Single non-curable factor & $14(66.7 \%)$ & $11(42.3 \%)$ & $27(33.8 \%)$ & 0.025 \\
\hline \multicolumn{5}{|l|}{ First line chemotherapy } \\
\hline S-1 alnoe & $1(4.8 \%)$ & $7(26.9 \%)$ & $15(18.7 \%)$ & \\
\hline + CDDP & $12(57.1 \%)$ & $5(19.2 \%)$ & $22(27.5 \%)$ & \\
\hline + Taxane (DTX/ PTX) & $2(9.5 \%)$ & $1(3.9 \%)$ & $12(15.0 \%)$ & \\
\hline$+\mathrm{CDDP}+\mathrm{DTX}$ & $2(9.5 \%)$ & $0(0 \%)$ & $3(3.8 \%)$ & \\
\hline Capecitabine + CDDP & $1(4.8 \%)$ & $0(0 \%)$ & $4(5.0 \%)$ & \\
\hline Other regimens & $3(14.3 \%)$ & $13(50.0 \%)$ & $24(30.0 \%)$ & \\
\hline Second-line chemotherapy & $19(90.5 \%)$ & $19(73.1 \%)$ & $58(72.5 \%)$ & 0.169 \\
\hline Chemotherapy period, months, median (range) & $14.2(2.1-31.5)$ & $14.1(0.2-44.1)$ & $7.2(0.2-51.4)$ & $<0.001$ \\
\hline
\end{tabular}

aSome cases overlapped.

95\% CI $=0.019-0.650, \quad p=0.011)$. Further analysis was performed to see what was important to achieve R0 resection. R0 resection was significantly more achieved when there was a single non-curable factor and no distant organ metastasis ( $p=0.007$ and $p=0.024$, respectively) (Table IV).

We analyzed whether the timing of gastrectomy affected the surgical outcomes. R0 resection was achieved in 9 patients $(42.9 \%)$ in the Perioperative chemotherapy-group, while no patients achieved $\mathrm{R} 0$ resection and mostly had $\mathrm{R} 2$ resection in the Postoperative chemotherapy-group. However, other factors did not differ between the two groups.

\section{Discussion}

Our results showed that chemotherapy followed by curative gastrectomy improves the survival for UGC. There are some reports showing that $\mathrm{R} 0$ resection had a better survival than those without it (13-16). In our study, R0 resection was achieved in 9 cases $(19.1 \%)$ of those who had gastrectomy and all of these cases had preoperative chemotherapy. The benefit of preoperative chemotherapy can be explained by several reasons. First, preoperative chemotherapy contributes to a high complete resection rate due to antitumor effects on the primary lesion and lymph node metastases tumor, which were also observed in our study (17). Second, preoperative chemotherapy has a better compliance than postoperative chemotherapy. This is because, gastrectomy leads to higher

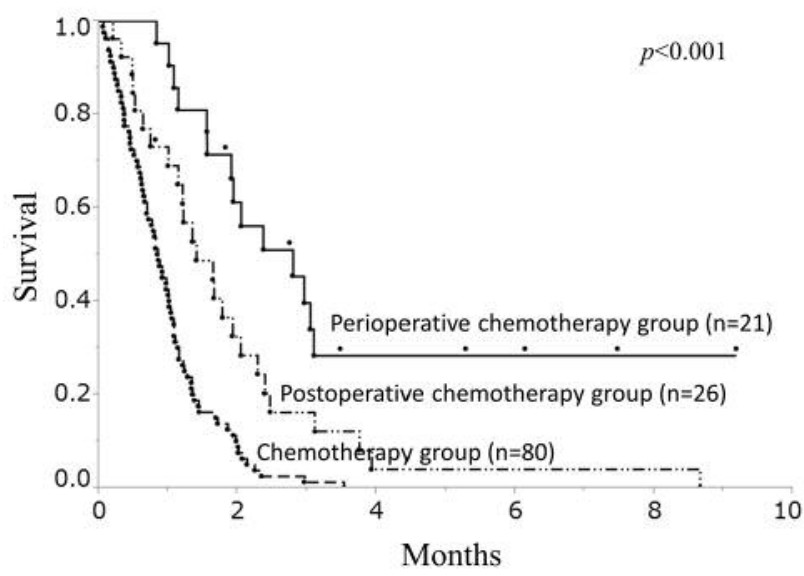

Figure 2. Overall survival according to the treatment.

chemotherapeutic toxicity and body weight loss is a risk factor for interrupting the chemotherapy $(18,19)$. Third, preoperative chemotherapy gives time to confirm whether any new lesions appear. These advantages raise the possibility that patients who respond well to chemotherapy may have a benefit from subsequent R0 resection (20). Moreover, our study showed that $\mathrm{R} 0$ resection is primarily achieved when there is a single non-curable factor without distant organ metastasis. 
Table II. Prognostic factors of all patients.

\begin{tabular}{|c|c|c|c|c|c|c|}
\hline \multirow[t]{2}{*}{ Variables } & \multicolumn{3}{|c|}{ Univariate analysis } & \multicolumn{3}{|c|}{ Multivariate analysis } \\
\hline & HR & $95 \% \mathrm{CI}$ & $p$-Value & HR & $95 \% \mathrm{CI}$ & $p$-Value \\
\hline Performance status $0 / 1$ & 0.282 & $0.156-0.565$ & $<0.001$ & 0.252 & $0.123-0.551$ & 0.001 \\
\hline Histology (differentiated type) & 0.778 & $0.535-1.122$ & 0.180 & 0.564 & $0.377-0.837$ & 0.004 \\
\hline $\mathrm{T} 4$ & 1.024 & $0.696-1.540$ & 0.905 & & & \\
\hline Bulky lymph node metastasis & 0.906 & $0.555-1.415$ & 0.676 & & & \\
\hline Distant lymph node metastasis & 1.251 & $0.869-1.796$ & 0.227 & & & \\
\hline $\mathrm{CY}$ and/or $\mathrm{P}$ factor & 1.476 & $1.023-2.127$ & 0.038 & 1.151 & $0.761-1.732$ & 0.503 \\
\hline Distant organ metastasis & 1.731 & $1.200-2.510$ & 0.003 & 2.573 & $1.579-4.257$ & $<0.001$ \\
\hline Single non-curable factor & 0.450 & $0.305-0.654$ & $<0.001$ & 0.639 & $0.393-1.028$ & 0.065 \\
\hline Gastrectomy & 0.300 & $0.195-0.452$ & $<0.001$ & 0.242 & $0.149-0.384$ & $<0.001$ \\
\hline Second-line chemotherapy & 0.503 & $0.333-0.782$ & 0.003 & 0.274 & $0.168-0.447$ & $<0.001$ \\
\hline
\end{tabular}

HR: Hazard ratio; CI: confidence interval; CY and/or P factor: positive peritoneal cytology and/or peritoneal metastasis.

Table III. Prognostic factors of those who underwent gastrectomy.

\begin{tabular}{|c|c|c|c|c|c|c|}
\hline \multirow[t]{2}{*}{ Variables } & \multicolumn{3}{|c|}{ Univariate analysis } & \multicolumn{3}{|c|}{ Multivariate analysis } \\
\hline & HR & $95 \% \mathrm{CI}$ & $p$-Value & HR & $95 \% \mathrm{CI}$ & $p$-Value \\
\hline Performance status $0 / 1$ & 0.078 & $0.018-0.538$ & 0.015 & 0.129 & $0.022-1.053$ & 0.055 \\
\hline Histology (differentiated type) & 0.543 & $0.268-1.050$ & 0.070 & 0.705 & $0.333-1.446$ & 0.341 \\
\hline $\mathrm{T} 4$ & 1.108 & $0.578-2.231$ & 0.763 & & & \\
\hline Bulky Lymph node metastasis & 0.552 & $0.162-1.423$ & 0.238 & & & \\
\hline Distant lymph factor metastasis & 1.092 & $0.557-2.074$ & 0.792 & & & \\
\hline $\mathrm{CY}$ and/or $\mathrm{P}$ factor & 2.205 & $1.152-4.220$ & 0.017 & 1.391 & $0.657-2.933$ & 0.385 \\
\hline Distant organ metastasis & 1.571 & $0.824-3.019$ & 0.169 & 0.989 & $0.348-2.813$ & 0.984 \\
\hline Single non-curable factor & 0.430 & $0.223-0.819$ & 0.010 & 0.804 & $0.308-2.055$ & 0.651 \\
\hline $\mathrm{R} 0$ resection & 0.097 & $0.016-0.323$ & $<0.001$ & 0.140 & $0.019-0.650$ & 0.011 \\
\hline Preoperative Chemotherapy & 0.425 & $0.214-0.809$ & 0.009 & 0.841 & $0.364-1.870$ & 0.673 \\
\hline Second-line chemotherapy & 1.076 & $0.498-2.682$ & 0.862 & & & \\
\hline
\end{tabular}

HR: Hazard ratio; CI: confidence interval; CY and/or P factor: positive peritoneal cytology and/or peritoneal metastasis.

Table IV. Patients characteristics of those who underwent preoperative chemotherapy.

\begin{tabular}{lccc}
\hline Variables & $\begin{array}{c}\text { R0 resection group } \\
(\mathrm{n}=9)\end{array}$ & $\begin{array}{c}\mathrm{R} 1 / 2 \text { resection group } \\
(\mathrm{n}=12)\end{array}$ & $p$-Value \\
\hline Performance status 0/1 & $9(100 \%)$ & $11(91.7 \%)$ & $5(41.7 \%)$ \\
Histology (differentiated type) & $5(55.6 \%)$ & 1.000 & 0.000 \\
T4 3(33.3\%) & $5(41.7 \%)$ & $1(8.3 \%)$ & 0.570 \\
Non-curable factor & & $5(41.7 \%)$ & 0.670 \\
$\quad$ Bulky lymph node & $2(22.2 \%)$ & $4(33.3 \%)$ & 0.338 \\
Distant lymph node metastasis & $5(55.6 \%)$ & $8(66.7 \%)$ & 0.024 \\
CY and/or P factor & $1(11.1 \%)$ & $5(41.7 \%)$ & 0.007 \\
$\quad$ Distant organ metastasis & $1(11.1 \%)$ & $19(90.5 \%)$ & 0.169 \\
Single non-curable factor & $9(100 \%)$ & $13.4(4.4-30.7)$ & 0.804 \\
Second line chemotherapy & $7(77.8 \%)$ & & \\
Chemotherapy period, months, median (range) & $14.9(2.1-31.5)$ & & \\
\hline
\end{tabular}

CY and/or P factor: Positive peritoneal cytology and/or peritoneal metastasis. aSome cases overlapped. 
In our study, patients with non-curative resection had a significantly better survival than chemotherapy alone. However, the REGATTA trial demonstrated that initial removal of the primary tumor has no benefit compared to chemotherapy alone (10). This paradoxical result could be explained by focusing on the patients' background. In the REGATTA trial, stage IV GC patients who had single noncurable factor were enrolled to the study, while multiple non-curable factors are often observed in the clinical practice $(10,11)$. Patients with multiple non-curable factors are known to have a poor prognosis (5); however, when chemotherapy was performed prior to gastrectomy, multiple non-curable factors were no longer associated with poor prognosis (11). Also, patients with bleeding or obstruction who required palliative gastrectomy were excluded from the REGATTA trial. Our results showed that duration period of chemotherapy was significantly longer in those who had $\mathrm{R} 1 / 2$ resection than those with chemotherapy alone. This might be because gastrectomy avoided interrupting the chemotherapy due to urgent symptoms, such as bleeding or obstruction. R1/2 resection with chemotherapy might have a benefit over chemotherapy alone; however, further study is needed.

There are several limitations of this study. First, it was not a randomized trial and carried out by a single institution. Second, first-line chemotherapy regimen differed in cases. S-1 plus cisplatin or oxaliplatin is now widely used as an initial chemotherapy regimen that might affect the survival $(5,6,8)$. Third, there is a selection bias since patients who were performed gastrectomy had less non-curable clinical factors. Last, we cannot exclude the fact that we mainly operated patients who responded to chemotherapy in the Perioperative chemotherapy-group.

In conclusion, curative operation after chemotherapy has an advantage in improving the survival for initially UGC. Also, patients treated with non-curative gastrectomy have a chance of having a longer chemotherapy period than chemotherapy alone that might associate with better survival.

\section{References}

1 Yoshida M, Ohtsu A, Boku N, Miyata Y, Shirao K, Shimada Y, Hyodo I, Koizumi W, Kurihara M, Yoshida S and Yamamoto S: Long-term survival and prognostic factors in patients with metastatic gastric cancers treated with chemotherapy in the Japan Clinical Oncology Group (JCOG) study. Jpn J Clin Oncol 34: 654-659, 2004.

2 Bang YJ, Van Cutsem E, Feyereislova A, Chung HC, Shen L, Sawaki A, Lordick F, Ohtsu A, Omuro Y, Satoh T, Aprile G, Kulikov E, Hill J, Lehle M, Rüschoff J and Kang YK and ToGA Trial Investigators: Trastuzumab in combination with chemotherapy versus chemotherapy alone for treatment of HER2-positive advanced gastric or gastro-oesophageal junction cancer (ToGA): a phase 3, open-lebel, randomised controlled trial. Lancet 376: 687-697, 2010.
3 Koizumi W, Narahara H, Hara T, Takagane A, Akiya T, Takagi M, Miyashita K, Nishizaki T, Kobayashi O, Takiyama W, Toh Y, Nagaie T, Takagi S, Yamamura Y, Yanaoka K, Orita H and Takeuchi M: S-1 plus cisplatin versus S-1 alone for first-line treatment of advanced gastric cancer (SPIRITS trial): a phase III trial. Lancet Oncol 9: 215-221, 2008.

4 Fukuchi M, Mochiki E, Ishiguro T, Ogura T, Sobajima J, Kumagai Y, Ishibashi $\mathrm{K}$ and Ishida H; Efficacy of nab-paclitaxel as second-line chemotherapy for unresectable or recurrent gastric cancer. Anticancer Res 36: 6699-6703, 2016.

5 Fukuchi M, Ishiguro T, Ogata K, Suzuki O, Kumagai Y, Ishibashi K, Ishibashi K, Ishida H, Kuwano $\mathrm{H}$ and Mochiki E: Prognostic Role of Conversion Surgery for Unresectable Gastric Cancer. Ann Surg Oncol 22: 3618-3624, 2015.

6 Ito S, Oki E, Nakashima Y, Ando K, Hiyoshi Y, Ohgaki K, Saeki $\mathrm{H}$, Morita M, Sakaguchi Y and Maehara Y: Clinical significance of adjuvant surgery following chemotherapy for patients with initially unresectable stage IV gastric cancer. Anticancer Res 35: 401-406, 2015.

7 Kinoshita J, Fushida S, Tsukada T, Oyama K, Okamoto K, Makino I, Kinoshita J, Fushida S, Tsukada T, Oyama K, Okamoto K, Makino I, Nakamura K, Miyashita T, Tajima H, Takamura H, Ninomiya I and Ohta T: Efficacy of conversion gastrectomy following docetaxel, cisplatin, and S-1 therapy in potentially resectable stage IV gastric cancer. Eur J Surg Oncol 41: 1354-1360, 2015.

8 Fukuchi M, Mochiki E, Ishiguro T, Ogura T, Sobajima J, Kumagai $\mathrm{Y}$, Ishibashi $\mathrm{K}$ and Ishida $\mathrm{H}$ : Efficacy of conversion surgery following S-1 plus cisplatin or oxaliplatin chemotherapy for unresectable gastric cancer. Anticancer Res 37: 1343-1347, 2017.

9 Yoshida K, Yamaguchi K, Okumura N, Tanahashi T and Kodera Y: Is conversion therapy possible in stage IV gastric cancer: the proposal of new biological categories of classification. Gastric Cancer 19: 329-338, 2016.

10 Fujitani K, Yang HK, Mizusawa J, Kim YW, Terashima M, Han SU, Iwasaki Y, Hyung WJ, Takagane A, Park DJ, Yoshikawa T, Hahn S, Nakamura K, Park CH, Kurokawa Y, Bang YJ, Park BJ, Sasako $\mathrm{M}$ and Tsujinaka T; REGATTA study investigators: Gastrectomy plus chemotherapy versus chemotherapy alone for advanced gastric cancer with a single non-curable factor (REGATTA): a phase 3, randomised controlled trial. Lancet Oncol 17: 309-318, 2016.

11 Tokunaga M, Makuuchi R, Miki Y, Tanizawa Y, Bando E, Kawamura T, Terashima M: Surgical and survival outcome following truly palliative gastrectomy in patients with incurable gastric cancer. World J Surg 40: 1172-1177, 2016.

12 Japanese Gastric Cancer Association: Japanese classification of gastric carcinoma: 3rd English edition. Gastric Cancer 14: 101112,2011

13 Lasithiotakis K, Antoniou SA, Antoniou GA, Kaklamanos I and Zoras O: Gastrectomy for stage IV gastric cancer. a systematic review and meta-analysis. Anticancer Res 34: 2079-2085, 2014.

14 Saito M, Kiyozaki H, Takata O, Suzuki K and Rikiyama T: Treatment of stage IV gastric cancer with induction chemotherapy using S-1 and cisplatin followed by curative resection in selected patients. World J Surg Oncol 12: 406, 2014.

15 Satoh S, Okabe H, Teramukai S, Hasegawa S, Ozaki N, Ueda S, Tsuji A, Sakabayashi S, Fukushima M and Sakai Y: Phase II trial of combined treatment consisting of preoperative S-1 plus cisplatin followed by gastrectomy and postoperative S-1 for stage IV gastric cancer. Gastric Cancer 15: 61-69, 2012. 
16 Yamaguchi K, Yoshida K, Tanahashi T, Takahashi T, Matsuhashi N, Tanaka Y, Tanabe K and Ohdan H: The long-term survival of stage IV gastric cancer patients with conversion therapy. Gastric Cancer, 2017. doi: 10.1007/s10120-017-0738-1. [Epub ahead of print]

17 Schuhmacher C, Gretschel S, Lordick F, Reichardt P, Hohenberger W, Eisenberger CF, Haag C, Mauer ME, Hasan B, Welch J, Ott K, Hoelscher A, Schneider PM, Bechstein W, Wilke H, Lutz MP, Nordlinger B, Van Cutsem E, Siewert JR and Schlag PM: Neoadjuvant chemotherapy compared with surgery alone for locally advanced cancer of the stomach and cardia: European Organisation for Research and Treatment of Cancer randomized trial 40954. J Clin Oncol 28: 5210-5218, 2010.

18 Kodera $\mathrm{Y}$, Ishiyama A, Yoshikawa T, Kinoshita T, Ito S, Yokoyama H, Mochizuki Y, Ito H, Tsuburaya A, Sakamoto J and Nakao A; Chubu Clinical Cancer Group: A feasibility study of postoperative chemotherapy with S-1 and cisplatin (CDDP) for gastric carcinoma (CCOG0703). Gastric Cancer 13: 197-203, 2010 .
19 Aoyama T, Kawabe T, Fujikawa H, Hayashi T, Yamada T, Tsuchida K, Yukawa N, Oshima T, Rino Y, Masuda M, Ogata T, Cho $\mathrm{H}$ and Yoshikawa $\mathrm{T}$ : Loss of Lean Body Mass as an Independent Risk Factor for Continuation of S-1 Adjuvant Chemotherapy for Gastric Cancer. Ann Surg Oncol 22: 25602566, 2015.

20 Han DS, Suh YS, Kong SH, Lee HJ, Im SA, Bang YJ, Kim WH and Yang HK: Outcomes of surgery aiming at curative resection in good responder to induction chemotherapy for gastric cancer with distant metastases. J Surg Oncol 107: 511-516, 2013.

Received December 11, 2017

Revised February 5, 2018

Accepted February 6, 2018 